\title{
Comparative and Superlative Constructions in Alaskan Athabascan Languages
}

\author{
Siri G. Tuttle \\ University of Alaska Fairbanks
}

A survey of reported comparative constructions in the Koyukon, Ahtna and Tanana Athabascan languages of Alaska shows that many fall into Dixon's $(2008,2012)$ A2 class. A dimensional verb is accompanied by a modifying postpositional phrase, with the standard being the object of the postposition. Superlatives are not as well represented in lexical documentation as comparatives, which are themselves rare in texts and difficult to elicit. Structured elicitation of comparatives and superlatives in Ahtna and Koyukon supports observations that this rarity is related to cultural norms in Athabascan communities, where comparison (especially of people) can be considered rude, and superlatives evidence of inappropriate pride.

\section{Introduction}

Tanana (also referred to as Lower Tanana; now represented only by the Minto dialect, Benhti Kokht'ana Kenaga'), Koyukon (Denaakk'e) and Ahtna (Koht'aene Kenaege') are three of the eleven Athabascan languages spoken in Alaska. ${ }^{1}$ All three are closely related, though Tanana and Koyukon, which are geographically contiguous, feel closer, largely because of shared vocabulary.

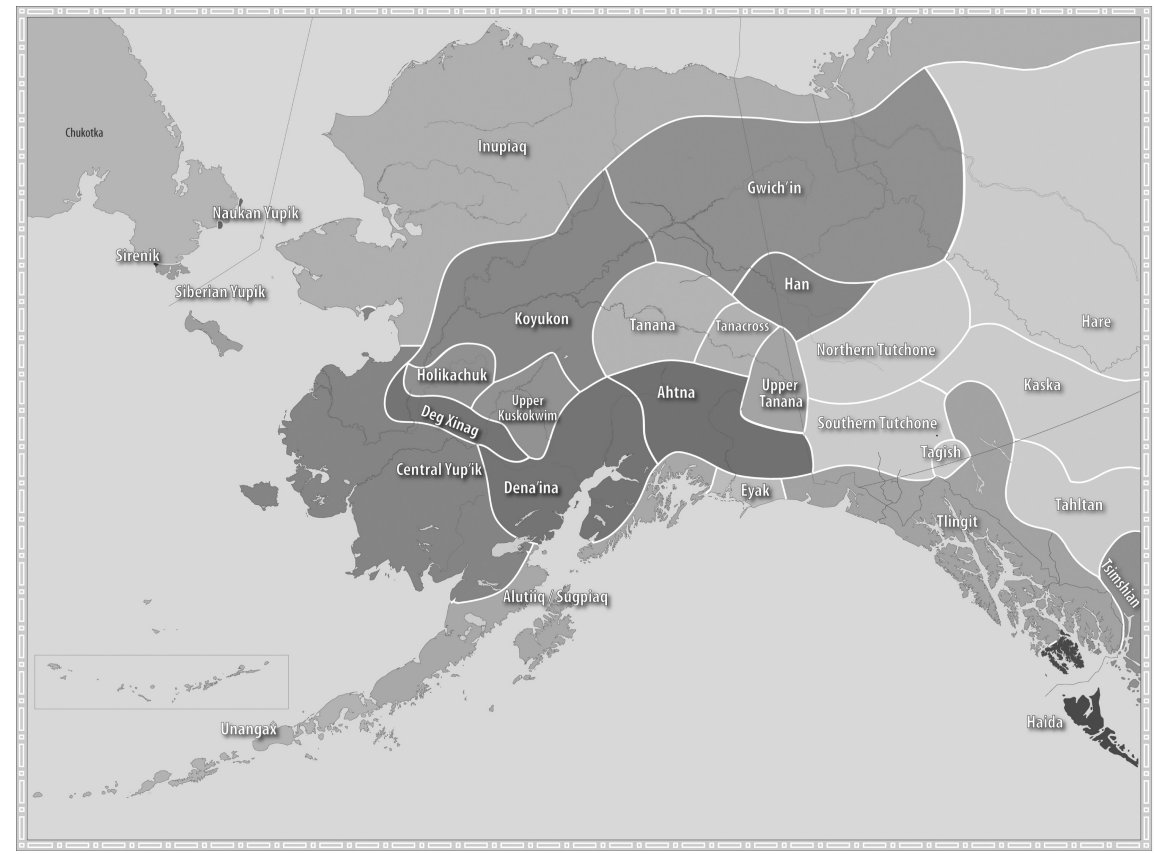

Figure 1. Indigenous peoples and languages of Alaska (Krauss et al. 2011)

Languages of the Athabascan family are found in three non-contiguous geographic areas in North America: Alaska and northwest Canada (the Northern group), the Southwest of the contiguous United States (the Apachean group) and along the west coast of the contiguous United States (the

\footnotetext{
${ }^{1}$ This research is supported by National Science Foundation project BCS1160654 and by the Alaska Native Language Center.
} 
Pacific Coast group). The languages represented in this study are all members of the Northern group.

The Athabascan languages are polysynthetic, primarily prefixing, and head-final. Verbs are often described in the Athabascanist literature using a morphological template; in this paper, glosses follow this convention. For purposes of the present discussion, a generalized template can be applied to these three languages, since the structure of the verb is one of the most consistent properties across the language family, and especially across the languages of Alaska's interior. The template shown in Table 1 roughly follows the conventions used in Kari (1990) and Jetté and Jones (2000).

\begin{tabular}{|c|c|c|c|c|c|c|c|c|c|c|c|c|c|c|}
\hline \multicolumn{5}{|c|}{ Disjunct } & \multicolumn{7}{|c|}{ Conjunct } & & \multicolumn{2}{|c|}{ Suffix } \\
\hline 11 & 10 & 9 & 8 & 7 & $6 a$ & $6 b$ & 5 & 4 & 3 & 2 & 1 & $\mathbf{0}$ & -1 & -2 \\
\hline $\begin{array}{l}0 \\
0 \\
0 \\
0 \\
0 \\
0 \\
0 \\
0 \\
0 \\
0 \\
0 \\
0 \\
0 \\
0 \\
0 \\
0\end{array}$ & 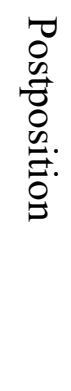 & $\begin{array}{l}\frac{d}{2} \\
\stackrel{0}{0} \\
0 \\
0 \\
0\end{array}$ & 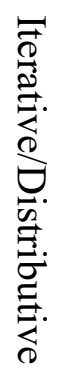 & 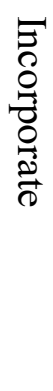 & 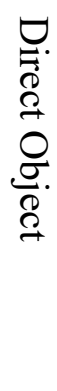 & 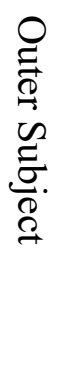 & 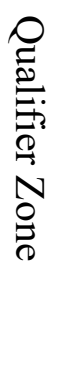 & 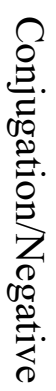 & $\frac{3}{2}$ & $\begin{array}{l}\underset{\sigma}{\sigma} \\
\underset{\sigma}{\sigma} \\
\stackrel{\sigma}{\sigma}\end{array}$ & $\begin{array}{l}\Omega \\
\stackrel{0}{0} \\
\tilde{N} \\
\vec{\oplus}\end{array}$ & $\frac{\mathscr{a}}{\vec{\theta}}$ & 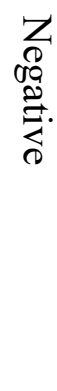 & 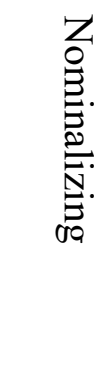 \\
\hline
\end{tabular}

Table 1. Reference template for Athabascan verbal forms

Positions in the template are numbered positively going leftward to prefixes from the stem. The negative numbers to the right of the stem indicate suffixes. In this morphological pattern, inflectional affixes frequently separate derivational prefixes, leading to an effect of interdigitation, rather than layering. This pattern is typical of the Athabascan family as a whole, though languages may vary in the details of individual affix order (Rice 2000).

In some verbs, only Positions 0 and 3 may have phonological content in Koyukon and Tanana; in Ahtna, a few verbs contain only a stem in Position 0, and no affixes. This is because the templatic organization of the verbal system allows for zero-elements (which will be notated $\varnothing$ - in this paper). Subject morphemes, "classifiers", mode, and conjugation may be, and often are, represented by a default null element in the template.

Structures used in description are shared over the three languages discussed here, though patterns, as well as lexical items, differ. However, depth and breadth of documentation varies, so that absence of a structure in documentation may not mean absence in the language. Grammars, per se, have not been written for these languages. The documentation for Koyukon is most complete, having been begun earliest with the work of Jules Jette in the early $20^{\text {th }}$ century, but even for this language, many infrequent structures have not been attested, though they may be hypothesized to exist. Many examples of grammar and usage have been compiled and organized by lexical entry in Jetté and Jones (2000), and that work provides the background for the present study.

In-depth documentation of Ahtna is represented by the long-term fieldwork of James Kari, much of which is archived at the Alaska Native Language Archive at the University of Alaska Fairbanks. Grammatical examples from this work are compiled and organized by lexical entry in 
his Ahtna-English dictionary (Kari 1990). Some grammatical explanation is found in Tuttle (2009b), a grammatical companion to Kari (1990).

Documentation for the Tanana language is the least extensive lexically, with comparative phonology and text collection by Krauss in the early 1960s (texts archived as Charlie et al. 1984, 1991), Kari's (1994) draft stem dictionary, which includes and organizes many examples from Krauss' texts, and Tuttle's (2009a) pocket dictionary.

While comparative and superlative constructions contain extraverbal elements, some background in Athabascan verbal morphology is required in order to clarify the examples in this paper. In Table 1, a descriptive reference template is presented for basic morpheme order in the three languages under consideration. Templates of this sort are used for descriptive purposes by Athabascanists, but do not constitute a theoretical representation of speaker knowledge.

Verb forms are listed lexically as "themes" in Northern Athabascan dictionaries, such as in Jetté and Jones (2000) for Koyukon. A theme consists of a root, often very abstract in meaning, along with lexically required prefixes that may or may not carry additional meaning. Other derivational prefixes may be added to define action, description or state of being more precisely, creating a verb base. Athabascan verbs are characterized by discontinuous constituency, since as Table 1 shows, derivational and inflectional elements in the verb are interspersed linearly, not built in contiguous layers.

There are very few true adjectives in the languages under discussion. Description is most often encoded in verbs. Such a verb consists of a descriptive root, possible morphological "gender" agreement with associated arguments, possible thematic modifiers, a productive or unproductive "classifier" that can mark valence, and stative aspectual morphology. These prefixes form a characteristic prefix string associated with descriptive verbs.

Such prefix strings are listed in Alaskan Athabascan dictionaries (Kari 1990, Jetté and Jones 2000) as aspectual derivational strings. Kari describes an aspectual derivational string as "a package (or formula) of prefixes and suffixes" (Kari 1990: 50). They are aspectual in that they require a particular conjugation pattern for aspect. These strings co-occur in semantically related verbs - motion verbs, for example, or in this case, descriptive verbs. They may be discontinuous since inflectional elements may occur between members of such strings.

Table 2 identifies some of the prefixes that will be shown to occur in the descriptive verbs in this paper, relative to the template in Table 1. 


\begin{tabular}{|c|c|c|c|c|c|c|c|c|c|c|c|c|c|c|}
\hline \multicolumn{5}{|c|}{ Disjunct } & \multicolumn{7}{|c|}{ Conjunct } & & \multicolumn{2}{|c|}{ Suffix } \\
\hline 11 & 10 & 9 & 8 & 7 & $6 a$ & $6 b$ & 5 & 4 & 3 & 2 & 1 & 0 & -1 & -2 \\
\hline 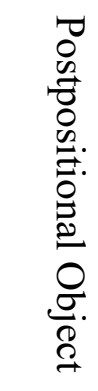 & 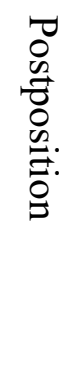 & 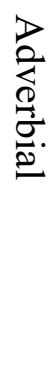 & 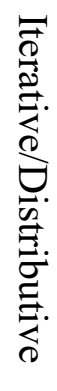 & $\begin{array}{l}\bar{\Xi} \\
\delta \\
\frac{0}{8} \\
0 \\
\stackrel{0}{0} \\
\overrightarrow{0}\end{array}$ & 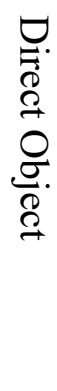 & 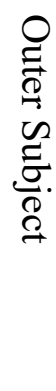 & 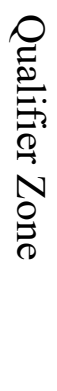 & 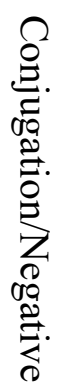 & $\begin{array}{l}3 \\
\frac{2}{0} \\
\frac{2}{8}\end{array}$ & $\begin{array}{l}\mathscr{\Xi} \\
\underset{\sigma}{\sigma} . \\
\stackrel{\sigma}{\sigma}\end{array}$ & 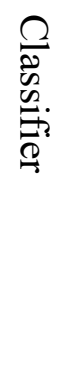 & $\underset{\vec{Q}}{\stackrel{\infty}{\Xi}}$ & 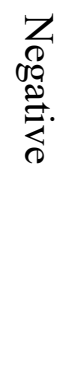 & : \\
\hline & & 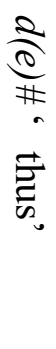 & & & & & 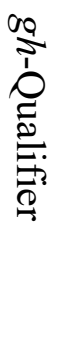 & 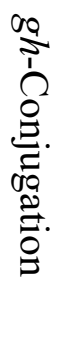 & 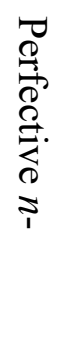 & & 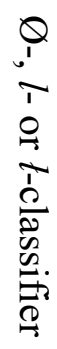 & & & \\
\hline
\end{tabular}

Table 2. Reference for Athabascan Prefixes

To take these in left-to-right order:

- Position 9: $d$ - 'thus' is described as a "subsidiary" prefix by Jules Jetté in his grammar of Koyukon (see quotation in Jetté and Jones 2000: 126). In Kari's lexical work (Kari 1990, 1994) it is described as a "pro-verb" prefix. It is found in copular, positive, equative, and comparative forms, as well as in verbs that can replace other verbs in replies. This prefix does not form part of a substitution set.

- Position 5: Adverbial and gender prefixes occur in the qualifier zone. "Gender" includes agreement for properties of the verbal arguments. Gender prefixes include $n-, d-, l-, g h-, \varnothing-$ and the areal prefix, which has varied forms depending on the language. These prefixes do not increase valence.

- Position 4: gh-conjugation is found in the positive and comparative morphology of description.

- Position 3: Perfective $n$ - is found in the positive and comparative morphology of description.

- Position 1: "Classifiers" do not classify anything; this conventional term is opaque, but because the substitution set is inconsistent in its behavior, it cannot easily be replaced with a functional term. When productive, the $t$-classifier can add an argument, and the $\varnothing$-, $l$ - and $d$ classifiers can correlate with lowered valence. However, classifier selection is also lexicalized as an element in derivational aspectual strings. 
As will be shown in this paper, different combinations of the elements in Table 2 are found in positive, equative, comparative and superlative constructions in the three languages. Note that even within this restricted set of prefixes, homophonous prefixes can exist, such as the $g h$-qualifier and gh-conjugation in Koyukon.

Because of the close morphological resemblances among all the Athabascan languages, linguists often consult works on related languages when investigating structures that are not fully described in the language they work with directly. Navajo, an Athabascan language of the Apachean sub-group, is one of the most-studied languages of the family. Bochnak and BogalAllbritten's (2015) paper on comparison presents Navajo data that is morphologically similar to the findings presented in this paper (i.e., verbal morphology for dimensional adjectival verbs is parallel, as is the use of locational structures to indicate comparative relationships), though Navajo boasts a wider variety of adjectival forms than any of the languages discussed here. BogalAllbritten's earlier work on Na-Dene comparatives (2010) presents examples from Slave, Witsuwit'en (both northern Athabascan languages) and Tlingit (a member of the larger Na-Dene family that includes the Athabascan group).

\section{Examples in Lexicons}

In the following section, archived and published examples from Tanana, Koyukon and Ahtna are presented first, since these provided the basis on which recent fieldwork has been done. Examples cited from published and unpublished dictionaries come from various sources, which are not annotated in these dictionaries; some are drawn from texts, and others were the result of elicitation. The citation of the dictionary does not, therefore, constitute a complete identification of the data, but will allow the reader to find the example for further examination and comparison.

Comparative and superlative structures are exemplified in published and unpublished dictionaries for Ahtna, Koyukon and Tanana (Kari 1990, Kari 1994, Jetté and Jones 2000, Tuttle 2009a). The examples below are presented in the local orthographies. An orthographic equivalence chart is given in Appendix A, as the languages share many phonemes that are written differently in the orthographies.

In (1), the cognates of the adjectival verb that means 'big, tall, high' in the three languages are shown in context. In (1a), the areal gender prefix $k h w$ - must be used to agree with the meaning of the argument 'house'; the cognate prefix $h t$ - is used in the Koyukon example (1b), and ko- in the Ahtna example (1c), to indicate the otherwise unmentioned referent. ${ }^{2}$

(1) Being big

(1a) Tanana

Yekh khuchokh.

yekh Ø- $\quad k h w-\quad \varnothing-\quad n-\quad \varnothing-\quad c h o k h$

house 3S.SBJ QUAL CNJ PVF CLF be.big/tall.IPFV

'The house is big.' (Kari 1994: 50)

\footnotetext{
2 Abbreviations used in glosses: ADV Adverbial, AR Areal, CLF Classifier, CNJ Conjugation, COMP Complementizer, CUST Customary, DM Discourse marker, FOC Focus, G Gender, INDEF Indefinite, IPFV Imperfective, NEG Negative, OBJ Object, P Plural, PP Postposition, PPO Object of postposition, PFV Perfective, PSSR Possessor, QUAL Qualifier, REFL Reflexive, REL Relativizer, S Singular, SBJ Subject, SUPRL Superlative, TOP Topical, TRANS Transitional
} 
(1b) Koyukon

Bekk'aakk'aa hookoh.

be- kk'aakk'aa Ø- hu- $\varnothing$ - ne- $\varnothing$ - koh

3S.PSSR tracks 3S.SBJ QUAL CNJ PFV CLF be.big.IPFV

'Its [an animal's] tracks are big.' (Jetté and Jones 2000: 349)

(1c) Ahtna

Katcaax.

Ø- $\quad k o-\quad g h-\quad \varnothing-\quad$ t- caax

3S.SBJ QUAL CNJ IPFV CLF be.big.IPFV

'It [an area] is big.' (Kari 1990: 109)

The glosses in (1) show that the morphology of the adjectival verb is different in Ahtna than in the other two languages. In the positive form, Tanana and Koyukon use the $n$-perfective prefix, which phonology renders vocalic. These forms have no classifier. Ahtna, however, does use the $t$ classifier, but not the $n$-perfective prefix.

Comparison of superiority is often accompanied by changes in morphology, as well as the use of locational elements, such as postpositions. The Tanana example in (2) shows the use of a postposition as the standard marker. $d$ - 'thus' is the item that seems best identified as a degree marker; the inner section of the verb, including stem, classifier, qualifiers and aspect marking, is grouped together as Parameter.

(2) Superiority: Tanana

Peter yontha deghiłchokh.

\begin{tabular}{llllllll} 
NP & P & Verb Word & & & & \\
Peter & yontha & $d-$ & $\varnothing-$ & $g h-$ & $i-$ & $t-$ & chokh \\
Peter & ahead.of & thus & 3S.SBJ & CNJ PFV & CLF & be.big/tall.IPFV \\
Standard & Standard Marker & Degree & Comparee & Parameter & & \\
\multicolumn{1}{r}{} & Marker & & & &
\end{tabular}

In Ahtna, the cognate aspectual string occurs in positive forms as well as in equative and comparative forms, as shown in (3).

(3) Ahtna positive dimensional with $d e \# g h+l$ aspectual derivational string

Dghitcaax

$d-\quad$ O- $\quad g h-\quad n-\quad t-\quad c a a x$

thus 3S.SBJ CNJ PFV CLF be.big/tall.IPFV

'It is big.' (Kari 1990: 109)

In Ahtna, the aspectual string $d e \# g h+l$ appears to perform a basic descriptive function, while in Tanana and Koyukon, the data presented in published lexicons suggests that it is specific to comparative constructions. Kari (1990: 130) refers to the $d$-prefix in this Ahtna string as the "proverb" prefix, though in the Koyukon documentation (Jetté and Jones 2000: 126) the cognate prefix is called "subsidiary" following Jetté's terminology. The morphological and syntactic behavior of these cognate prefixes establishes their cognate status. 
The $d$ - "proverb" or "subsidiary" prefix is translated 'thus', in a number of its instantiations. This prefix seems to change the complement possibilities of a verb to include reference to a clause. Jetté, quoted in Jetté and Jones (2000: 126) observes:

The subsidiary de...occurs in the subsidiary verbs, in which its meaning is properly that of a demonstrative, viz.: thus, in such a circumstance or condition. The subsidiary verbs...are those that can replace other verbs in answers, or in independent propositions.

Ahtna $d$ - 'thus', along with $g h$-conjugation, does not appear when a gender prefix, such as the areal ko-, is present in an Ahtna dimensional verb. Thus it is not present in (1c) above. Kari (1990: 130) states that these prefixes do not occur in combination with gender, but does not indicate whether this should be considered a morphological or a phonological alternation. Variation also exists in these patterns over the Ahtna dialects (Kari 1990: 130).

Comparison of equality over a parameter may be expressed using a postpositional phrase, verbal morphology including $d$ - 'thus', or the particle $k$ ' $e$ 'like'. The examples in (4) vary across the languages and employ different combinations of these comparative tools. In (4a), $d$ - 'thus' cooccurs with a postpositional standard marker, but in (4b), this prefix alone is used. In the Ahtna examples in (4c), $d$ - 'thus' does not occur, and only the standard marker is used. Note that in (4a), the parameter has to be shown as discontinuous in order to identify the comparee.

(4) Equality

(4a) Koyukon

Sekk'e deghonlekuh.

\begin{tabular}{|c|c|c|c|c|c|c|c|}
\hline PPO & PP & Verb Prefix S & ring & & & & Verb Stem \\
\hline & $k k^{\prime} e$ & $d e-$ & $g h-$ & $g h-$ & $n-$ & le- & $-k u h$ \\
\hline l S.OB. & equivalent & thus & QUAL & $\mathrm{CNJ}$ & $2 \mathrm{~S} . \mathrm{SBJ}$ & CLF & be.big.IPFV \\
\hline Standard & Standard Marker & Degree Marker & Parame & & Comparee & & Parameter \\
\hline
\end{tabular}

'You are as big as me.' (Jetté and Jones 2000: 355)

(4b) Tanana

Dinadhedi .... seyina' deghiłchokh.

\begin{tabular}{|c|c|c|c|c|c|c|c|}
\hline NP & NP & Verb & ring & & & & Verb Stem \\
\hline Dinadhedi & seyina' & $d e-$ & $\varnothing-$ & gh- & $i-$ & $t-$ & -chokh \\
\hline
\end{tabular}

Standard Comparee Degree Marker Comparee Parameter

'My mind is as big as Denali (aka Mt. McKinley).' (Tuttle 2009a: 132)

(4c) Ahtna

Koht'aenn ce'e 'iinn k'e 'entcaax.

\begin{tabular}{llllll} 
PPO & PP & \multicolumn{2}{l}{ Verb Prefix String } & Verb Stem \\
Koht'aenn ce'e 'iinn & $k$ 'e & $\emptyset$ - & $n-\quad t-$ & -caax \\
big men & equivalent & 3S.SBJ & PFV CLF & be.big.IPFV \\
Standard & Standard Marker & Comparee & Parameter &
\end{tabular}

'They are as tall as big men.' (Kari 1990: 109)

Note that $d$ - 'thus' seems to work on its own as a degree marker in the Tanana example in (4b), but occurs along with the postposition $k k$ 'e in the Koyukon example in (4a). The redundancy of $d$ - 
'thus' in the Koyukon example is reminiscent of its apparent inertness in the Ahtna dimensional string $d \# g h+t$. It is not unusual for individual Athabascan prefixes that form part of derivational strings to become bleached in meaning - merely lexical - in some contexts, while remaining productive in others.

Morphological devices for the expression of equative comparison are summarized in (5).

(5) Strategies in equative constructions 'as big as'

\begin{tabular}{|c|c|c|c|c|c|c|c|c|c|}
\hline \multirow[t]{2}{*}{ PRO } & \multirow[t]{2}{*}{$\mathrm{PP}$} & \multicolumn{6}{|c|}{ Verb Prefix String } & \multirow{2}{*}{$\begin{array}{l}\text { Verb } \\
\text { Stem }\end{array}$} & \multirow[t]{2}{*}{ Language } \\
\hline & & $\begin{array}{l}d- \\
\text { thus }\end{array}$ & $\begin{array}{l}g h- \\
\text { QUAL }\end{array}$ & $\begin{array}{l}g h- \\
\text { CNJ }\end{array}$ & $\begin{array}{l}n- \\
\text { PFV }\end{array}$ & $\begin{array}{l}t- \\
\text { CLF }\end{array}$ & $\begin{array}{l}l- \\
\mathrm{CLF}\end{array}$ & & \\
\hline NP & $k k^{\prime} e$ & + & + & + & + & & + & $\begin{array}{l}-k u h \\
\text { be.big }\end{array}$ & Koyukon \\
\hline NP & & + & & + & + & + & & $\begin{array}{l}\text {-chokh } \\
\text { be.big }\end{array}$ & Tanana \\
\hline NP & $k^{\prime} e$ & & & & + & + & & $\begin{array}{l}\text {-caax } \\
\text { be.big }\end{array}$ & Ahtna \\
\hline Standard & $\begin{array}{l}\text { Standard } \\
\text { Marker }\end{array}$ & $\begin{array}{l}\text { Degree } \\
\text { Marker }\end{array}$ & \multicolumn{6}{|c|}{ Parameter } & \\
\hline
\end{tabular}

Morphological strategies in comparative constructions (comparison of superiority) are similar to those used in equative constructions: postpositions serve as standard markers along with $d$ - 'thus', as a degree marker, and the rest of the dimensional aspectual derivational string forms the finite verb, the parameter. Examples from published lexicons are shown in (6).

(6) Comparative Constructions

(6a) Koyukon

Benonte deyegholkuh.

\begin{tabular}{llllllll} 
PPO & PP & \multicolumn{2}{c}{ Verb Prefix String } & \multicolumn{3}{c}{ Verb Stem } \\
be- & nonte & $d-$ & ye- & $g h-$ & $g h-$ & $l-$ & $-k u h$ \\
3OBJ-TOP & beyond & thus & 3.SBJ & QUAL & CNJ & CLF & be.big.IPFV \\
Standard & Standard Marker & Degree Marker & Comparee & Parameter & & \\
'He/she is bigger than him/her.' (Jetté and Jones 2000: & 297) & &
\end{tabular}

(6b) Tanana

Peter yontha deghitchokh.

\begin{tabular}{llllllll} 
PPO & PP & \multicolumn{2}{c}{ Verb Prefix String } & \multicolumn{3}{c}{ Verb Stem } \\
Peter & yontha & $d-$ & $\varnothing-$ & $g h-$ & $n-$ & $t-$ & - chokh \\
& beyond & thus & 3. SBJ & CNJ & PFV & CLF & be.big.IPFV \\
Standard & Standard Marker & Degree Marker & Comparee & Parameter & &
\end{tabular}

'He/she is bigger than Peter.' (Kari 1994: 50) 
(6c) Ahtna

\begin{tabular}{|c|c|c|c|c|c|c|c|}
\hline NP & $\mathrm{P}$ & Verb P & tring & & & & Verb Stem \\
\hline 'Atna' & $\begin{array}{l}\text { yits'ae } \\
\text { beyond }\end{array}$ & $\begin{array}{l}d- \\
\text { thus }\end{array}$ & $\begin{array}{l}\varnothing- \\
3 \mathrm{SBJ}\end{array}$ & $\begin{array}{l}g h- \\
\text { CNJ }\end{array}$ & $\begin{array}{l}n- \\
\text { PFV }\end{array}$ & $\begin{array}{l}t- \\
\text { CLF }\end{array}$ & $\begin{array}{l}\text {-tiy } \\
\text { be.strong.IPFV }\end{array}$ \\
\hline Standard & $\begin{array}{l}\text { Standard } \\
\text { Marker }\end{array}$ & $\begin{array}{l}\text { Degree } \\
\text { Marker }\end{array}$ & Comparee & Parar & & & \\
\hline
\end{tabular}

Superlatives share syntactic structure with comparatives, in that standards are represented as objects of postpositions. However, the examples in published lexicons are less consistent in structure than examples of comparatives.

However, a superlative takes as its standard one of a set of indefinite pronouns: $c$ '- in Ahtna, $c h$ ' $e$ - in Tanana and $k$ ' $e$ - in Koyukon form one cognate set of indefinite prefixes that are found as direct and indirect objects, possessors and subjects within verbal forms. However, another element, $h t$ - in Koyukon, $k h w$ - in Tanana (not found so far in Ahtna examples) can also represent the indefinite pronoun in this context. Jetté is quoted in Jetté and Jones (2000: 266) regarding this element, that it expresses "a remarkably greater shade of indetermination". This prefix is homophonous with a prefix known as the "Areal", which can function as a modifier, an object, or a subject in a verb form.

(7) Superlativity

(7a) Ahtna

C'astanizu'

c'- asta $\quad$ Ø- $\quad n^{-} \quad i_{-} \quad \emptyset_{-} \quad z u^{\prime}$

INDEF.OBJ SUPRL 3S.SBJ CNJ PFV CLF be.beautiful.CLF

Standard Standard Marker Comparee Parameter

'She is the prettiest.' (Lit., 'she out-beauties anyone') (Kari 1990: 208)

(7b) Lower Koyukon

K'ehuk'ots'e huyet deneye

k'eht-k'ots'e ht- yet $\emptyset_{-} \quad d-\quad \emptyset_{-} e_{-} \quad \emptyset_{-}$ney- $e$

foremost-ahead INDEF.OBJ with 3S.SBJ QUAL CNJ IPFV CLF know.IPFV REL

Standard Standard Comparee Parameter Comparee Marker

'Lead dog' (Jetté and Jones 2000: 316)

In (7a) (Ahtna), the standard is represented by the indefinite object $c$ '-. In this example, the indefinite standard $c$ '- seems to be best translated as 'anyone', though the set to which 'she' belongs is not apparent in this lexicon example. The standard marker is a superlative string made up of postpositional and modifying prefixes listed by Kari (1990: 208) as $P+g h a+s+t a$, which subcategorizes for the $n$-perfective. In the Ahtna form we do not see an element that could be identified as a degree Marker.

In the Koyukon example, the adverbial k'ehtk'ots'e is a compound of k'eht 'farthest' and $k$ 'ots' $e$ 'ahead'. K'eht itself is complex, as it combines the indefinite object $k$ ' $e$ - and -thtu, which Jetté and Jones translate as "comparative". The indefinite object/subject/possessor, $k$ ' $e$ - in Koyukon, has multiple roles in grammar; it can serve as a dummy object in a transitive verb, but it can also stand in for a force of nature acting as agent. The areal prefix, $h t$ - in Koyukon, is 
similarly versatile. It can represent a natural subject (weather), agree with a nominal in gender, or refer to the situation in general. When the two are combined, as in the Koyukon example in (5c), a possible gloss could be 'farthest-ahead'. The lead dog is the smartest being in the situation (that being the set of dogs on the line of a particular sled).

It will be noted that I have not provided a published example of a grammatical superlative from Tanana, because the published materials do not contain one. This foreshadows the dearth of examples to be found in corpora for these languages.

The examples shown here, all drawn from published sources, show that morphosyntactic structures exist in Tanana, Koyukon and Ahtna that can be used to express comparison. Adjectival stative verbs are used in description, and comparative and superlative constructions are formed by combining these verbs with locational phrases.

\section{Going beyond the lexicons}

Though grammatical strategies for expressing comparison are clearly present, as evidenced by lexical documentation, non-elicited examples are not easy to find. This is particularly true for superlatives. Examples of superlatives in available documentation are relatively few compared to simple descriptions, and even in comparison with comparatives.

To provide a rough idea of the scarcity of these expressions in texts: for this paper, a set of ten archived texts in Tanana were consulted (Charlie et al. 1991), along with a set of Ahtna texts in preparation for publication (Kari and Tuttle to appear), and a set of Koyukon texts from a variety of sources, currently being prepared for inclusion in a grammatical database. All three sets of texts contain a variety of genres, including memoirs, myths and historical material. None of these texts contain any morphosyntactic comparatives, though other strategies for comparison are used.

It is important to note that some comparisons are inherent in lexical sets. For example, the kinship systems in all three languages include lexemes that mean, in themselves, 'older brother,' 'younger sister,' etc. Thus, a story that contrasts the attributes of two siblings (a common device in Athabascan storytelling) often does so as in the Ahtna example in (8). In this example, details of morphology have been omitted. The word for 'older sister', -adae, is prefixed with the indefinite possessor $c^{\prime}$-, as is the word for 'younger sister', -daedze', providing the indefinite form that introduces the characters.

(8) From Kudadzaey Ts'akae "Spider Woman", by Martha Jackson

$C$ 'adae 'ele' i'dits 'iile c'edaedze' kughiya' konii.

C'adae 'ele'i'dits'iile c'edaedze' kughiya' konii

an.older.sister did.not.listen a.younger.sister was.smart it.is.said

'There was an older sister who didn't listen, and a younger sister who was smart, it is said.'

(Kari and Tuttle to appear)

In a language without such inherently comparative lexemes, the beginning of this story might have required morphosyntactic comparison. In Ahtna, however, the kin terms provide the contrast along with the non-parallel clauses, describing the two girls using different parameters, at least on the surface. The metaphor of "not listening", or "not having ears" is used to describe people who choose to ignore the teaching of elders, while "being smart" is applied to successful characters who follow cultural norms, and usually also turn out to be lucky. Listening, we conclude, is part of being smart; so in effect, the younger girl is the smarter one - but she is not described exactly that way in an Ahtna story. 
There is likely a cultural component to the avoidance of superlatives; Eliza Jones, Denaakk'e (Koyukon) elder and co-author of Jetté and Jones (2000), observes (p.c.) that traditional modes of speech avoid any appearance of boasting or even calling attention to the speaker's self, which an extreme comparison or a superlative may suggest. A textual example from Tanana (9, examined for morphology in Example 4b) demonstrates the possible consequences of extreme comparison.

Structurally, this extreme claim is formed as an equative construction. It uses the dedicated comparative morphology. Standard and Comparee precede the verb, and $d$ - 'thus' serves as degree marker. However, because the character in the story is comparing his mind to the size of the highest mountain in North America, he is expressing a metaphorical superlative.

(9) Tanana story Tsidoghe Tthi' To', recorded July 20, 2007 by the late Neal Charlie.

"Dinadhedi, nodo Dinadhedi go lo k'u seyina' deghitchokh," dungha 'at deghini'.

"My mind is as big as Denali," he told his older brother.

Dinadhedi 'Denali' $=$ Standard

seyina' 'my mind' = Comparee

deghitchokh 'it is (this) big' Degree Marker + Parameter

In the story from which this quotation comes, the boastful speaker is physically removed from power very soon after he makes this speech. This is part of the moral of the story. The act of boasting is shown to be followed by an extreme punishment.

This avoidance of boastful claims seems to be a part of a larger set of restrictions, which generally prescribe modest behavior and careful speech. While younger Athabascans move somewhat freely between the world of European-Americans, with its challenge to stand up for oneself, market oneself, promise and predict, elders often remind them of the rules, thinking of possible consequences. While these rules are not formally grammaticized, they are encoded in language behavior among the elders who serve as our grammatical mentors.

\section{Elicitation with graded stimuli}

In order to learn more about use and avoidance of grammatical comparison strategies, a structured elicitation activity was used. A small set of pictures was prepared to use in elicitation, to learn more about how speakers of these languages would describe a "standard" set of objects that are gradable using one property or another. Pictures of people's feet, of kettlebells, of dogs, of different shades of red, of mountains, and of the checkpoints on the Iditarod Trail, among other things, were used as stimuli. Examples from two speakers, one of Ahtna and one of Koyukon, will be presented here.

Despite the availability of morphosyntactic comparatives and superlatives in all three languages, as documented in lexical research, there was considerable variety of expression in response to the arrangement of supposedly gradable properties in series. A set of increasingly happy faces (Fig 2) received the responses given in (7 and 8): 

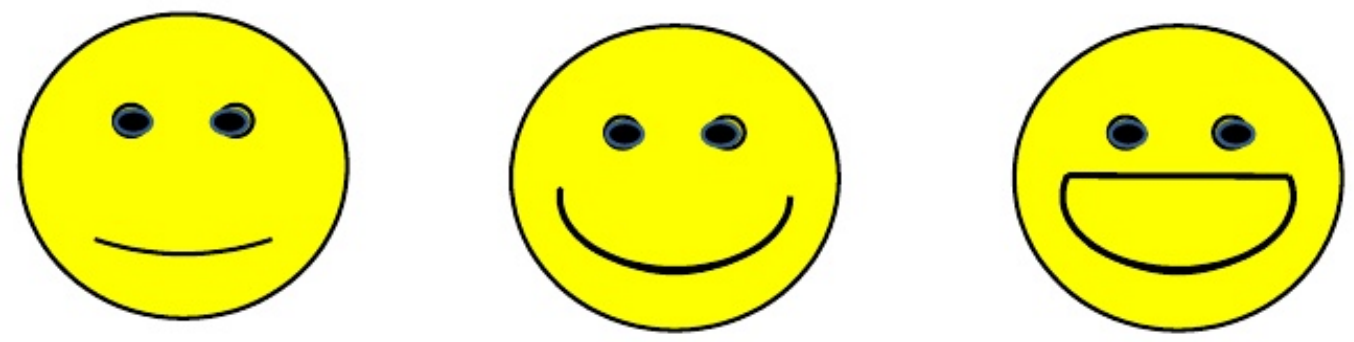

Figure 2: Happy, happier, happiest?

Instead of using a single gradable property, the sets of three were very commonly described using different, categorical properties.

(10) Ahtna (Tuttle field notes, March 2015)

(10a) Basuhwde'aa.

$b-\quad a-\quad s u-\quad \varnothing_{-} \quad h w-\quad d-\quad \varnothing_{-} \quad e_{-} \quad \varnothing_{-} \quad ' a a$

3.OBJ to happiness 3S.SBJ QUAL QUAL CNJ IPFV CLF linear.extends.IPFV

'S/he's happy.'

(10b) Basuhwdi'a'.

$\begin{array}{lllllllll}b- & a- & s u- & \varnothing- & h w- & d- & i- & \varnothing- & \text { ' } a\end{array}$

3.OBJ to happiness 3S.SBJ QUAL QUAL TRANS CLF linear.extends.PFV

'S/he became happy.'

(10c) Yen c'edlok.

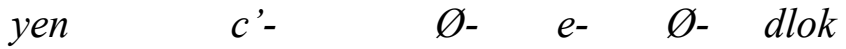

this.person INDEF.OBJ 3.SBJ IPFV CLF laugh.IPFV

'This person is laughing.'

(11) Koyukon (Tuttle field notes, May, 2015)

(11a) Gonh soodek'enaalget, kk'aant'aa.

Gonh soo- de- $k^{\prime} e^{-} \quad \varnothing_{-} \quad n-\quad$ aal- $\varnothing$ - $\quad$ get $\quad k k^{\prime} a a n t ' a a$ this. ADV REFL INDEF.OBJ 3S.SBJ QUAL CNJ Ø.CLF fear.IPFV appears person

'This one looks grumpy.'

(11b) Sodelts'eey huyoze.

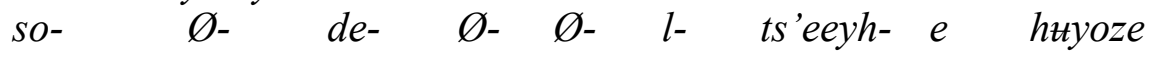
pleasant 3S.SBJ QUAL CNJ IPFV CLF happy REL a.little '(S)he's a little bit happy.'

(11c) Gonh het nek'edlukk.

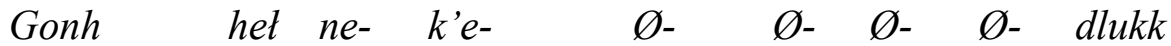

this.person DM ADV INDEF.OBJ 3S.SBJ CNJ IPFV CLF laugh.IPFV

'This one is laughing.' 
The responses in (10) and (11) certainly compare impressions of the three images, but they do not use the available morphosyntactic pattern that could compare over the same parameter. These descriptions are typical of the responses we were able to elicit.

Indirect encoding of descriptions is seen in other strategies in texts. For example, the use of huyoze 'a little' in Koyukon has an interesting twist. In texts and conversation, hwyoze is often interpreted backwards, indicating not "a little" but "a lot" or "all the time", as in (12).

(12) From the autobiography of Sally Pilot (translated by Eliza Jones; Tuttle and Jones fieldnotes)

K'eetde hwyoze to naangge ts 'eetl'oot deghtl-'aan'.

k'eet-de hwyoze to naangge ts'eetl'ool de- gh- , $\varnothing-s_{-} \quad t$ - 'aan' one-time a.little FOC upriver towline thus CNJ PFV 1S.SBJ CLF do.PFV

'Oh, a good many times I pulled boat going up the river.'

Eliza Jones (p.c.) also calls attention to a non-segmental strategy used to intensify description. This effect is represented in (13). A high tone is placed on a word stem (usually a verb stem, but here on the modifier edenh.) This tone is used along with vowel lengthening to intensify descriptive verbs (similar to faaaaaar away in English) but in her analysis of this text, also indicates repetition of actions and contrast focus.

Ts'eetl'oot deghtl-'eek denh kkaaken edénh koonh.

ts'eetl'oot de- gh- ø- $s_{-} \quad t$ - 'eek denh kkaaken edenh koonh towline thus CNJ PFV 1S.SBJ CLF do.CUST TIME boots absent even 'I pulled boat many times, not even wearing boots.'

Further study is needed to define the relationship of this intonational pattern to the comparative and superlative system represented by segmental structures. This note from Dr. Jones should be investigated further in the light of the claims made in this paper, since non-lexical suprasegmental effects have not been represented in grammatical sources for this language.

Sometimes, the standard is presented as the best example of the property being discussed. Another example in the elicitation set shows three great mountains of Alaska, Denali, St. Elias and Foraker. Ex. (14) is Dr. Jones' response to the request to compare them. Instead of starting with the smaller Foraker (17,400 feet, 5,304 m), Dr. Jones starts with the great Denali $(20,237$ feet, 6,168 meters) and works down through the middling St. Elias (18,008 feet, 5,489 meters).

(14) Mountains, compared; Koyukon (Tuttle notes, May 2015)

(14a) Go Deenaalee go hunonte, degholnet,

go Deenaalee go ht-nonte de- $\varnothing_{-} \quad g h-\quad g h-\emptyset_{-} t_{-}$net this Denali FOC AR-beyond thus 3S.SBJ QUAL CNJ PFV CLF be.tall.IPFV deghotkoh go North America.

de- $\quad$ - $\quad g h-\quad g h-\quad \varnothing-\quad t-\quad k o h \quad$ go $\quad$ North America thus 3S.SBJ QUAL CNJ PFV CLF be.big.IPFV this 'Denali is the tallest, the largest in North America.' 
(14b) Mount Saint Elias eet huts'enh hookoh

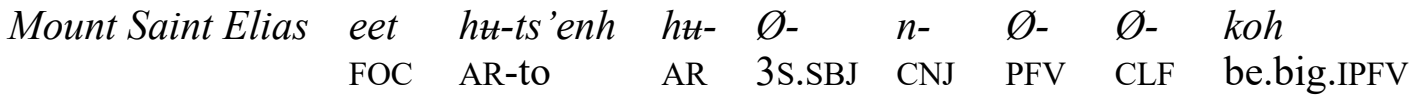

deghołkoh.

de- $\quad$ - $\quad$ gh- $g h-\quad \varnothing_{-} \quad t-\quad k o h$

thus 3S.SBJ QUAL CNJ PFV CLF be.big.IPFV

'Mt. St. Elias is the next biggest.' (next to Denali)

(14c) Teey etkughe

$\begin{array}{llllllll}\text { Teey } & \varnothing- & \varnothing- & \varnothing- & t- & \varnothing- & k t g h- & e\end{array}$

not.much 3S.SBJ CNJ PFV NEG CLF be.big.IPFV NEG

ts'eht dent'aa

ts'eht $\quad d e-\quad \varnothing-\quad \varnothing_{-} \quad n-\quad \varnothing_{-} \quad t^{\prime} a a$

in.the.manner.of thus 3S.SBJ CNJ PFV CLF be.IPFV

'It's not very big.'

(14d) Go Mt. Foraker hetde, Deenaalee Be'ot beeznee hetde

Go Mt.Foraker helde, Deenaalee Be-'ot beeznee hetde,

this DM Denali 3.PSSR-wife called DM

teey etkughe.

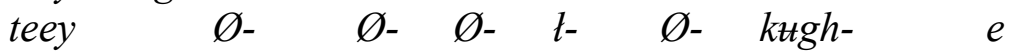

not.much 3S.SBJ CNJ PFV NEG CLF be.big.IPFV NEG

'Mt. Foraker now, the one they call Deenaalee's Wife, is not so big.'

In this comparison of the mountains, the same parameter is used for all the parts of the description. The description of Denali (14a) uses the morphosyntactic superlative, with the areal gender prefix performing the role of indefinite standard. The description of Mount St. Elias (14b) uses the comparative morphosyntax in the verb, though it does not use a postpositional phrase to state the standard, but rather the areal prefix in hutsenh, since the standard was introduced in the first sentence. (14c) and (14d) do not use comparative morphology. This example was the one in the elicitation set least likely to create a conflict with cultural norms, since the size of the mountains is beyond question. This is likely to be one reason for the direct use of the comparative morphology.

The existence of morphosyntactic comparative and superlative constructions in lexical and grammatical documentation makes clear that with the correct context, speakers of Ahtna, Tanana and Koyukon can use these expressions. However, this small experiment with elicitation suggests that the context must delimit the possibilities for degrees of the property being used, and, in addition, that the use of morphological comparison between entities, over an identical parameter is rarely the chosen form; instead, other strategies are used. 


\section{Summary}

A survey of reported comparative constructions in three Athabascan languages of Alaska shows that many fall into Dixon's (2008) A2 class: parameters are expressed using adjectival neuter verbs, with standard markers tending to be expressed in postpositional (spatial or time-related) form.

However, even in lexical documentation, superlative examples are rare. Spontaneous and elicited responses involving comparison also show avoidance of morphosyntactic superlatives, and even of comparing different entities over the same parameter. Cultural norms may affect these patterns, with modest and cautious expression being highly valued. Incomplete knowledge does not provide an acceptable base for claiming that an entity is the "most" anything.

A proverbial saying included in Jetté and Jones (2000: 704) encodes these values:

(15) A quotation from Catherine Attla, a famous Koyukon storyteller (Jetté and Jones 2000: 704) Nugh nelo hoogudze, nedaakoon hookoh ts'e hugh heneehaayh.

'Your mouth is too small, don't talk about big things.'

("Said to children who talk about the great things they are going to do, or who repeat adults' gossip or criticism of another person.")

\section{References}

Bochnak, M. Ryan and Elizabeth Bogal-Allbritten. 2015. Investigating gradable predicates, comparison and degree constructions in underrepresented languages. In: Bochnak, M. Ryan and Lisa Matthewson (eds.), Methodologies in Semantic Fieldwork, pp. 110-134. Oxford: Oxford University Press.

Bogal-Allbritten, Elizabeth. 2010. Distribution and function of comparative aspect in Athabaskan/Dene. In: Tuttle, Siri and Justin Spence (eds.), Working Papers in Athabaskan Languages 8 [Proceedings of the 2009 Athabaskan Languages Conference], pp. 19-32. Fairbanks: Alaska Native Language Center.

Charlie, Moses, Michael Krauss and James Kari. 1991. The Moses Charlie Collection. Ms., ANLC Archive. TNMN 981 K1991d.

Charlie, Teddie, Michael Krauss, Ellen Frank and Jane McGary. 1984. Menteekheghottheet, Old Minto. Ms. In ANLC Archive. TNMN 984 C1984.

Dixon, R.M.W. 2008. Comparative constructions: A cross-linguistic typology. Studies in Language 32(4), 787-817.

Dixon, R.M.W. 2012. Comparative constructions (Chapter 26). In: Basic Linguistic Theory: Further Grammatical Topics. Vol. III: 343-375. Oxford University Press, Oxford.

Jetté, Jules and Eliza Jones. 2000. Koyukon Athabaskan Dictionary. Fairbanks: Alaska Native Language Center.

Kari, James. 1990. Ahtna Athabaskan Dictionary. Fairbanks: Alaska Native Language Center.

Kari, James. 1994. Lower Tanana Athabaskan Dictionary. Digital file in author's possession; archived as Alaska Native Language Archive TNMN981K1994b.

Kari, James and Siri Tuttle. (to appear) Yenida'a, Tsuts'aede, K'adiide: Mythical Times, Ancient Times, Recent Times. An Anthology of Ahtna Narratives. Fairbanks: Alaska Native Language Center.

Krauss, Michael, Gary Holton, Jim Kerr, and Colin West. 2011. Indigenous Peoples and Languages of Alaska. Alaska Native Language Center and University of Alaska Anchorage Institute of Social and Economic Research. 
Rice, Keren. 2000. Morpheme Order and Semantic Scope. Cambridge: Cambridge University Press.

Stassen, Leon. 2013. Comparative constructions. In: Dryer, Matthew S. and Martin Haspelmath (eds.), The World Atlas of Language Structures Online. Leipzig: Max Planck Institute for Evolutionary Anthropology. Available online at: http://wals.info/chapter/121

Tuttle, Siri. 2009a. Benhti Kokht'ana Kenaga', Lower Tanana Pocket Dictionary. Fairbanks: Alaska Native Language Center.

Tuttle, Siri. 2009b. Ahtna Athabaskan Grammar Reference. Chistochina: Mt. Sanford Tribal Consortium.

\section{Appendix A: Orthographic comparison: Koyukon, Tanana, Ahtna}

This table compares symbols used in the practical orthographies to IPA symbols. Vowels are compared only for quality, not for length. For some consonants, a single symbol may be interpreted over a range of articulations, more commonly in Ahtna; thus multiple IPA symbols may be associated with one orthographic symbol. Not all phones represented in orthographies are phonemes.

\begin{tabular}{|c|c|c|c|}
\hline IPA & Koyukon Orthography & Lower Tanana Orthography & Ahtna Orthography \\
\hline$a$ & o & o & $\mathrm{a}$ \\
\hline$æ$ & aa & $\mathrm{a}$ & ae \\
\hline $\mathrm{i}$ & ee & $\mathrm{i}$ & ii \\
\hline 0 & $\mathrm{O}$ & o & \\
\hline $\mathrm{u}$ & 00 & $\mathrm{u}$ & $\mathrm{uu}$ \\
\hline U & u & W & $\mathrm{u}$ \\
\hline$\varepsilon$ & e & e & e \\
\hline ว & $\mathrm{i}$ & e & $\mathrm{a}$ \\
\hline $\mathrm{p}$ & $\mathrm{b}$ & $\mathrm{b}$ & $\mathrm{b}$ \\
\hline $\mathrm{t}$ & $\mathrm{d}$ & $\mathrm{d}$ & $\mathrm{d}$ \\
\hline c & $\mathrm{g}$ & & $\mathrm{g}$ \\
\hline $\mathrm{k}$ & gg & $\mathrm{g}$ & \\
\hline$q$ & & & $\mathrm{k}$ \\
\hline$?$ & , & , & , \\
\hline $\mathrm{t}^{\mathrm{h}}$ & $\mathrm{t}$ & $\mathrm{t}$ & $\mathrm{t}$ \\
\hline $\mathrm{c}^{\mathrm{h}}$ & $\mathrm{k}$ & & $\mathrm{c}$ \\
\hline $\mathrm{k}^{\mathrm{h}}$ & $\mathrm{kk}$ & $\mathrm{k}$ & \\
\hline $\mathrm{q}^{\mathrm{h}}$ & & & $\mathrm{k}$ \\
\hline $\mathrm{t}^{\prime}$ & $\mathrm{t}^{\prime}$ & $\mathrm{t}^{\prime}$ & $\mathrm{t}^{\prime}$ \\
\hline$c^{\prime}$ & $\mathrm{k}^{\prime}$ & & $\mathrm{c}^{\prime}$ \\
\hline $\mathrm{k}^{\prime}$ & kk' & $\mathrm{k}^{\prime}$ & \\
\hline$q^{\prime}$ & & & $\mathrm{k}^{\prime}$ \\
\hline ts & $\mathrm{dz}$ & $\mathrm{dz}$ & $\mathrm{dz}$ \\
\hline $\mathrm{t} \int$ & & $\mathrm{j}$ & $\mathrm{dz}$ \\
\hline tt & $\mathrm{dl}$ & $\mathrm{dl}$ & $\mathrm{dl}$ \\
\hline $\mathrm{ts}^{\mathrm{h}}$ & ts & ts & ts \\
\hline $\mathrm{t} \int^{\mathrm{h}}$ & & $\mathrm{ch}$ & ts \\
\hline ts' & ts' & ts' & ts' \\
\hline
\end{tabular}




\begin{tabular}{|c|c|c|c|}
\hline $\mathrm{t}{ }^{\prime}$ & & ch' & ts' \\
\hline ts' & & tr' & \\
\hline t1' & $\mathrm{tl}^{\prime}$ & $\mathrm{tl}^{\prime}$ & $\mathrm{tl}^{\prime}$ \\
\hline $\mathrm{S}$ & $\mathrm{S}$ & $\mathrm{S}$ & $\mathrm{S}$ \\
\hline $\int$ & & $\mathrm{sh}$ & $\mathrm{S}$ \\
\hline $\mathrm{S}$ & & $\mathrm{sr}$ & \\
\hline ç & yh & yh & yh \\
\hline 1 & 1 & 1 & 1 \\
\hline $\mathrm{x} \sim \chi$ & $\mathrm{h}$ & $\mathrm{kh}$ & $\mathrm{X}$ \\
\hline $\mathrm{h}$ & $\mathrm{h}$ & $\mathrm{h}$ & $\mathrm{h}$ \\
\hline $\mathrm{Z}$ & $\mathrm{Z}$ & $\mathrm{z}$ & $\mathrm{z}$ \\
\hline 3 & & & $\mathrm{z}$ \\
\hline Z & & $\mathrm{zr}$ & \\
\hline $\mathrm{j}$ & $y$ & $\mathrm{y}$ & $\mathrm{y}$ \\
\hline 1 & 1 & 1 & 1 \\
\hline $\mathrm{g} \sim \mathrm{B}$ & gh & gh & gh \\
\hline $\mathrm{m}$ & $\mathrm{m}$ & $\mathrm{m}$ & \\
\hline $\mathrm{n}$ & $\mathrm{n}$ & $n$ & $\mathrm{n}$ \\
\hline$n_{0}$ & $\mathrm{nh}$ & $\mathrm{nh}$ & $\mathrm{nh}$ \\
\hline
\end{tabular}

